\title{
Aberrant right subclavian artery in a cadaver: a case report of an aortic arch anomaly
}

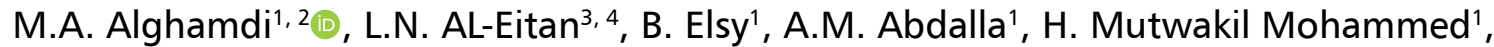 \\ A.G.A. Salih', S. Al Hilal Al Ghamdi ${ }^{5}$ \\ ${ }^{1}$ Department of Anatomy, College of Medicine, King Khalid University, Abha, Saudi Arabia \\ ${ }^{2}$ Genomics and Personalised Medicine Unit, College of Medicine, King Khalid University, Abha, Saudi Arabia \\ ${ }^{3}$ Department of Applied Biological Sciences, Jordan University of Science and Technology, Irbid, Jordan \\ ${ }^{4}$ Department of Biotechnology and Genetic Engineering, Jordan University of Science and Technology, Irbid, Jordan \\ ${ }^{5}$ Department of Surgery, College of Medicine, King Khalid University, Abha, Saudi Arabia
}

[Received: 18 April 2020; Accepted: 25 July 2020; Early publication date: 29 July 2020]

In early embryogenesis, aortic anomalies occur as a consequence of disorders in the development of the primitive aortic arches system. Aberrant right subclavian artery, also known as arteria lusoria, is one of the important congenital anomalies of the aortic arch, in which the right subclavian artery arises from the arch of aorta instead of the brachiocephalic trunk. During routine dissection of a female cadaver, we observed retro-oesophageal aberrant right subclavian artery arising as the fourth branch from the aortic arch. In this case, the brachiocephalic trunk was absent. Early detection of aortic arch anomalies through diagnostic interventions is helpful to avoid complications during surgical procedures. (Folia Morphol 2021; 80, 3: 726-729)

Key words: anatomical variant, aortic arch, retro-oesophageal, arteria lusoria

\section{INTRODUCTION}

Anatomical variations in the human body do exist externally and internally where the latter may be presenting some pathological consequences or a life-threatening factor during surgical procedures. Aberrant right subclavian artery (ARSA) is the commonest congenital aortic arch anomaly with an incidence of $0.5 \%$ to $1.8 \%$ [25]. ARSA, or arteria lusoria, is a rare anatomical variation in the general population and has a female predominance [13, 23]. Right subclavian artery (RSA) normally originates from the brachiocephalic trunk, but when this anomaly is present, the brachiocephalic trunk is absent. Therefore, four large arteries (i.e. right common carotid artery, left common carotid artery, left subclavian artery and RSA) arises from the aortic arch, in which the RSA has an aberrant origin arises from the most distal left side [16, 23]. This anomaly is frequently asymptomatic; however, in some cases, it may be associated with clinical symptoms such as compression, dysphagia (dysphagia lusoria), cough, and chest pain $[3,16,24,25]$. According to Vučurević et al. [27] aortic arch branching classification, type 4 pattern was found in this case report. Here, we report a case of a female cadaver with an ARSA and reviewed the aortic arch branching variations, its embryological development and clinical significances.

Address for correspondence: Dr. M.A. Alghamdi, King Khalid University PO Box 641, Abha, Asir Region, Postcode: 61421, Saudi Arabia, tel: 96617241 7866, Mobile: 966 505236044, e-mail: m.alghamdi@kku.edu.sa

This work was conducted at the Anatomy Department of King Khalid University (KKU), Abha, Saudi Arabia.

This article is available in open access under Creative Common Attribution-Non-Commercial-No Derivatives 4.0 International (CC BY-NC-ND 4.0) license, allowing to download articles and share them with others as long as they credit the authors and the publisher, but without permission to change them in any way or use them commercially. 


\section{CASE REPORT}

During a routine dissection at the Anatomy Department of King Khalid University, a female cadaver of unknown age was presented with a retro-oesophageal ARSA. The branches were carefully dissected to identify their courses and photographed.

We measured the diameters of the arch of aorta and its branches with a calliper. The diameter of the aortic arch was measured prior to the origin of the right common carotid artery. The descending aorta diameter was performed at a distance of $1 \mathrm{~cm}$ from the origin of the branching of ARSA. The diameters of the right common carotid, left common carotid, and left subclavian and aberrant right subclavian were measured at $1 \mathrm{~cm}$ from their origins (Table 1).

In the present case, we observed absences of brachiocephalic trunk and presences of four branches namely, right common carotid, left common carotid, left subclavian artery and ARSA from right to left side of the aortic arch (Fig. 1).

\section{DISCUSSION}

Normally during embryological development, the distal right dorsal aorta degenerates in the double aortic arches system. RSA develops from the right $4^{\text {th }}$ aortic arch and $7^{\text {th }}$ cervical intersegmental artery. In the case of ARSA, the right $4^{\text {th }}$ aortic arch, $7^{\text {th }}$ intersegmental artery, proximal and persistent distal right dorsal aorta involve in the formation of this cardiac malformation $[3,25,26]$. When aberrant, the RSA arises from the aortic arch distal to the left subclavian artery and crosses the midline causing compression [19, 25].

Despite the fact that the ARSA is a common aortic developmental anomaly, it is relatively a rare aberration in the general population with a female predominance [20]. The occurrence was more common in females (55.3\%) than males (44.7\%) [23], which is consistent with other reported studies $[13,18]$. In the current case, ARSA arises from the left side of the aortic arch as the last branch and passes behind the oesophagus.

This anomaly is mostly having a retro-oesophageal course (dorsal to the oesophagus) in the reported cases $(80 \%)$, passes between the trachea and the oesophagus $(15 \%)$, or anterior to the trachea in $5 \%$ of the cases $[10,19]$. Although most of the patients $(60-70 \%)$ are asymptomatic throughout their lives $[14,24]$, they are frequently diagnosed by incidental evaluations obtained for other reasons (i.e. imaging
Table 1. Measured diameters of the aortic arch and its branches in millimetres

\begin{tabular}{lc}
\hline Aortic arch & 28 \\
Descending aorta & 22 \\
Left common carotid artery & 8 \\
Right common carotid artery & 8 \\
Left subclavian artery & 9 \\
Aberrant right subclavian artery & 16 \\
\hline
\end{tabular}

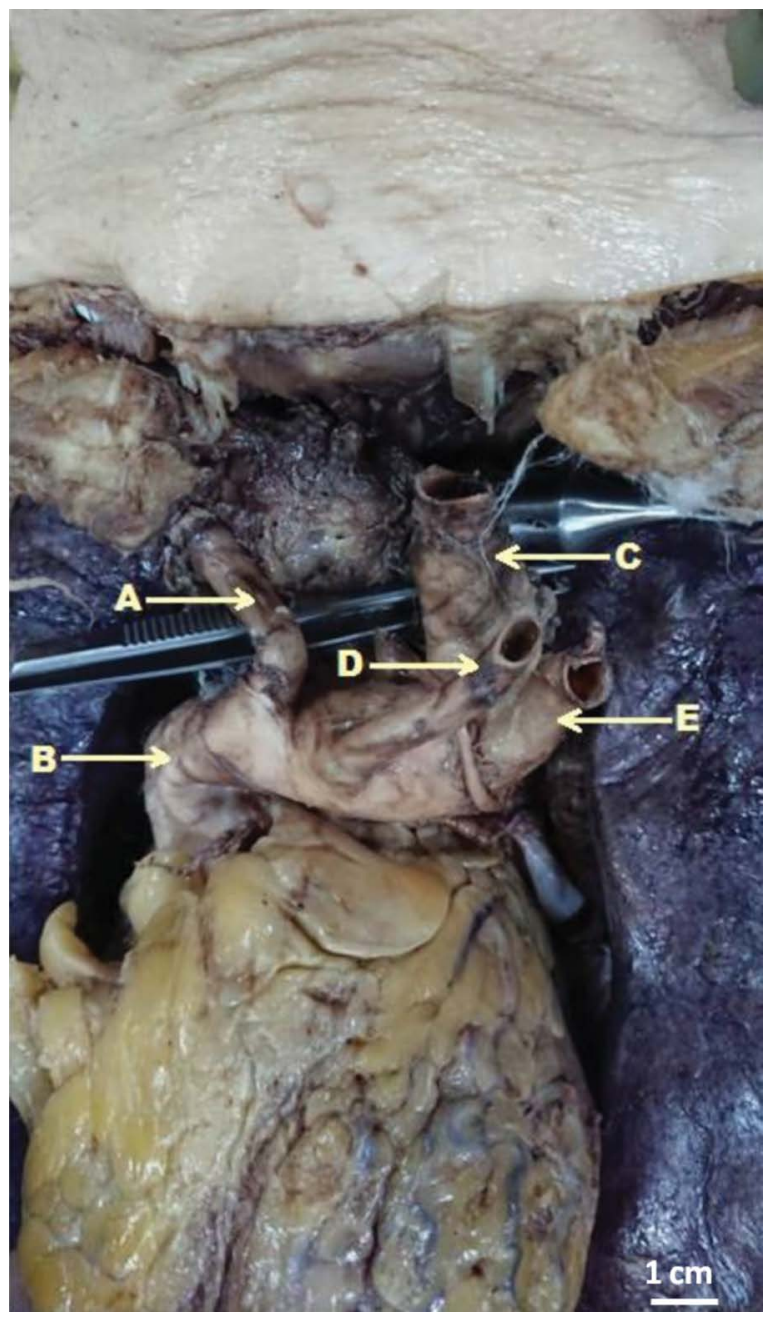

Figure 1. Right common carotid artery (A), aortic arch (B), retro-oesophageal aberrant right subclavian artery (C), left common carotid artery (D) and left subclavian artery (E).

and aortic dissection) [5, 11, 24]. If symptomatic, in adult patients ARSA usually produces dysphagia (dysphagia lusoria), cough, chest pain, shortness of breath and weight loss due to the compressive effect of the nearby structures $[19,23]$. An aneurysmal aortic dilatation, Kommerell's diverticulum occurs at 
the origin of the ARSA $[9,26]$. Increased frequency of pulmonary infections is more common in infants than adult patients; this is due to the absence of tracheal stiffness, in combination with dysphagia and aspiration of food particles [4].

In our case, the ARSA was $16 \mathrm{~mm}$ in diameter; same finding had been reported in another study [21]. The calibre of the aortic arch branches depends on the position of their origin. There is an association between the origin of the branches and the diameter of the aortic arch [17].

In right transradial approach for coronary angiography and angioplasty procedures, the presences of the ARSA increase the number of catheters and prolong angiography time. Before proceeding the techniques, the operator must gain a sound knowledge of the anatomical variations to decrease the complication rate $[1,2]$.

Many studies $[6,7,15]$ reported the correlation between foetal ARSA, intracardiac malformations and chromosomal abnormalities such as trisomy 21, 22q11 deletion of the long arm of the chromosome and Turner syndrome. Prenatal diagnosis of the ARSA is a useful marker for the ultrasonographic detection of foetal chromosomal abnormalities. In such cases, prenatal cytogenetic analysis is strongly recommended.

Treatment options such as conservative measures and surgical intervention mainly depend on the severity of the patient's symptoms and the presence of aneurysms [22]. Conservative measures are non-invasive treatments including dietary and lifestyle modifications often used for patients with mild to moderate symptoms $[19,22]$. This includes reducing or avoiding exacerbating foods, eating small bites of the food at a slower rate with adequate chewing, and having more liquids [22].

Several non-invasive angiography methods such as multislice and multidetector computed tomography, Doppler sonography, transthoracic echocardiography and the magnetic resonance imaging are essential for preoperative diagnosis of the ARSA. These methods help to avoid unintentional injury of this artery during surgical procedures $[8,12,28]$. Patients with severe symptoms, consideration for surgery should be taken as a variety of safe and effective surgical approaches have been proposed $[22,23]$.

\section{CONCLUSIONS}

Conclusively, anatomical variations are frequent, and the ARSA is a well-known anomalous with or without pathological consequences. Prenatal diagnosis of the ARSA through non-invasive angiography methods helps to detect the foetal chromosomal abnormalities. Sound knowledge of the course and relations of the ARSA is helpful to reduce the risk and complications in surgical procedures.

\section{Funding}

The authors would like to extend their appreciation to the Deanship of Scientific Research at King Khalid University for funding this project through general research program under grant number (G.R.P. 220/41).

\section{Acknowledgements}

The authors would like to express their gratitude to King Khalid University, Saudi Arabia, for providing administrative and technical support.

\section{Conflict of interest: None declared}

\section{REFERENCES}

1. Abhaichand RK, Louvard Y, Gobeil JF, et al. The problem of arteria lusoria in right transradial coronary angiography and angioplasty. Catheter Cardiovasc Interv. 2001; 54(2): 196-201, doi: 10.1002/ccd.1266, indexed in Pubmed: 11590683.

2. Allen $D$, Bews $H$, Vo $M$, et al. Arteria lusoria: an anomalous finding during right transradial coronary intervention. Case Rep Cardiol. 2016; 2016: 8079856, doi: 10.1155/2016/8079856, indexed in Pubmed: 27478652.

3. Aslan S, Elmalı M. An unusual cause of late-onset dysphagia; Aberrant right subclavian artery. South Clin Ist Euras. 2019; 30(3): 277-279, doi: 10.14744/scie.2019.44127.

4. Atay $\mathrm{Y}$, Engin $\mathrm{C}$, Posacioglu $\mathrm{H}$, et al. Surgical approaches to the aberrant right subclavian artery. Tex Heart Inst J. 2006; 33(4): 477-481, indexed in Pubmed: 17215974.

5. Battaloglu B, Secici S, Colak C, et al. Aberrant right subclavian artery and axillary artery cannulation in type a aortic dissection repair. Ann Thorac Surg. 2013; 96(1): e1-e2, doi: 10.1016/j.athoracsur.2013.01.044, indexed in Pubmed: 23816108.

6. Borenstein $M$, Minekawa R, Zidere $\mathrm{V}$, et al. Aberrant right subclavian artery at 16 to $23+6$ weeks of gestation: a marker for chromosomal abnormality. Ultrasound Obstet Gynecol. 2010; 36(5): 548-552, doi: 10.1002/uog.7683, indexed in Pubmed: 20503237.

7. Chaoui R, Thiel G, Heling KS. Prevalence of an aberrant right subclavian artery (ARSA) in fetuses with chromosomal aberrations. Ultrasound Obstet Gynecol. 2006; 28(4): 414-415, doi: 10.1002/uog.3047.

8. Chen X, Qu YJ, Peng ZY, et al. Diagnosis of congenital aortic arch anomalies in chinese children by multi-detector computed tomography angiography. J Huazhong Univ Sci Technolog Med Sci. 2013; 33(3): 447-451, doi: 10.1007/ s11596-013-1140-9, indexed in Pubmed: 23771676. 
9. Cinà CS, Althani H, Pasenau J, et al. Kommerell's diverticulum and right-sided aortic arch: a cohort study and review of the literature. J Vasc Surg. 2004; 39(1): 131-139, doi: 10.1016/j.jvs.2003.07.021, indexed in Pubmed: 14718830.

10. Domínguez EF, Corredera BM. Anomalies associated with aberrant right subclavian arteries. A case report. Eur J Anat. 2009; 13(1): 43-46.

11. Fernando RJ, Altman JM, Farmer B, et al. Aberrant right subclavian artery: an important variant of the aortic arch. Anesthesiology. 2019; 130(4): 615-616, doi: 10.1097/ ALN.0000000000002567, indexed in Pubmed: 30875358.

12. Hart PA, Kamath PS. Dysphagia lusoria. Mayo Clin Proc. 2012; 87(3): e17, indexed in Pubmed: 3497995.

13. Jain KK, Braze AJ, Shapiro MA, et al. Aberrant right subclavian artery-esophageal fistula and severe gastrointestinal bleeding after surgical correction of scimitar syndrome. Tex Heart Inst J. 2012; 39(4): 571-574, indexed in Pubmed: 22949782.

14. Janssen M, Baggen MG, Veen HF, et al. Dysphagia lusoria: clinical aspects, manometric findings, diagnosis, and therapy. Am J Gastroenterol. 2000; 95(6): 1411-1416, doi: 10.1111/j.1572-0241.2000.02071.x, indexed in Pubmed: 10894572

15. Lee SH, Jung JiMi, Song MS, et al. Evaluation of cardiovascular anomalies in patients with asymptomatic turner syndrome using multidetector computed tomography. J Korean Med Sci. 2013; 28(8): 1169-1173, doi: 10.3346/ jkms.2013.28.8.1169, indexed in Pubmed: 23960443.

16. Mahmodlou R, Sepehrvand N, Hatami S. Aberrant right subclavian artery: a life-threatening anomaly that should be considered during esophagectomy. J Surg Tech Case Rep. 2014; 6(2): 61-63, doi: 10.4103/2006-8808.147262, indexed in Pubmed: 25598945.

17. Manole AM, Iliescu DM, Rusali A, et al. Morphometry of the aortic arch and its branches. ARS Medica Tomitana. 2013; 19(3): 154-159, doi: 10.2478/arsm-2013-0027.

18. Molz G, Burri B. Aberrant subclavian artery (arteria lusoria): sex differences in the prevalence of various forms of the malformation. Evaluation of 1378 observations. Virchows Arch A Pathol Anat Histol. 1978; 380(4): 303-315, doi: 10.1007/BF00431315, indexed in Pubmed: 153045.

19. Naqvi SE, Beg $M H$, Thingam $S K$, et al. Aberrant right subclavian artery presenting as tracheoesophagial fistula in a 50-year-old lady: Case report of a rare presentation of a common arch anomaly. Ann Pediatr Cardiol. 2017; 10(2): 190-193, doi: 10.4103/apc.APC_158_16, indexed in Pubmed: 28566828.

20. Natsis K, Didagelos M, Gkiouliava A, et al. The aberrant right subclavian artery: cadaveric study and literature review. Surg Radiol Anat. 2017; 39(5): 559-565, doi: 10.1007/s00276-016-1796-5, indexed in Pubmed: 27999944.

21. Natsis K, Didagelos M, Manoli SM, et al. A bicarotid trunk in association with an aberrant right subclavian artery. Report of two cases, clinical impact, and review of the literature. Folia Morphol. 2011; 70(2): 68-73, indexed in Pubmed: 21630225.

22. Nik Qisti F, Shahrun Niza AS, Razrim R. Lusoria: a case report. Dysphagia. 2016; 15(2): 7376, doi: 10.31436/ imjm.v15i2.393 .

23. Polguj M, Chrzanowski $Ł$, Kasprzak JD, et al. The aberrant right subclavian artery (arteria lusoria): the morphological and clinical aspects of one of the most important variations: a systematic study of 141 reports. Sci World J. 2014; 2014: 292734, doi: 10.1155/2014/292734, indexed in Pubmed: 25105156.

24. Rosa P, Gillespie DL, Goff JM, et al. Aberrant right subclavian artery syndrome: a case of chronic cough. J Vasc Surg. 2003; 37(6): 1318-1321, doi: 10.1016/s07415214(02)75464-5, indexed in Pubmed: 12764282.

25. Saraceni C, Kwan WC, Joshi T, et al. Aberrant Right Subclavian Artery: A Rare Cause of Dysphagia. Am J Gastroenterol. 2018; 113(Suppl): S982-S983, doi: 10.14309/00000434-201810001-01720.

26. van Son JA, Konstantinov IE, Burckhard F. Kommerell and Kommerell's diverticulum. Tex Heart Inst J. 2002; 29(2): 109-112, indexed in Pubmed: 116736.

27. Vučurević G, Marinković S, Puškaš L, et al. Anatomy and radiology of the variations of aortic arch branches in 1,266 patients. Folia Morphol. 2013; 72(2): 113-122, doi: 10.5603/fm.2013.0019, indexed in Pubmed: 23740497.

28. Yang $M$, Mo X, Jin J, et al. [Diagnostic value of 64 multislice $\mathrm{CT}$ in typing of congenital aortic anomaly in neonates and infants]. Zhonghua Yi Xue Za Zhi. 2010; 90(31): 2167-2171, indexed in Pubmed: 21029654. 